\title{
Assessment of Polyamines and Trehalose in Wheat Microspores Culture for Embryogenesis and Green Regenerated Plants
}

\author{
Amina Redha, Patrice Suleman \\ Department of Biological Sciences, Faculty of Science, Kuwait University, Safat, Kuwait. \\ Email: aminaredha@gmail.com,psuleman96@gmail.com
}

Received September $24^{\text {th }}, 2013$; revised October $20^{\text {th }}, 2013$; accepted October $25^{\text {th }}, 2013$

Copyright (C) 2013 Amina Redha, Patrice Suleman. This is an open access article distributed under the Creative Commons Attribution License, which permits unrestricted use, distribution, and reproduction in any medium, provided the original work is properly cited.

\begin{abstract}
Most aspects of microspore culture protocol have the capacity to cause stress to microspores, hence, less stressful treatments might be required to avoid deleterious effects. In stressed plants, polyamines and trehalose can act as compatible solutes or osmoprotectants by stabilizing proteins and biological membranes. To improve green plant regeneration in wheat microspore culture, this study assessed the effects of polyamines (putrecine, spermidine, spermine) and trehalose on androgenic response namely embryogenesis, green plant regeneration and ploidy of green plants regenerated in three spring wheat genotypes. Microspores of the genotypes produced significant numbers of embryos and green plants among polyamine treatments but trehalose had no effect $(\mathrm{P} \leq 0.05)$. Polyamine treatments for 30 min generally produced more green plants per 100 microspores than the 60 min treatments in all three genotypes. At least three out of twelve polyamine treatments in each genotype improved the production of double haploid plants and seed setting in regenerants. Wheat genotype, concentration and duration of polyamine treatment had significant impact on embryogenesis and regeneration of green plants in this study. The study also showed that polyamines could be used to accelerate cultivar development in wheat breeding.
\end{abstract}

Keywords: Androgenesis; Microspore Culture; Polyamines; Trehalose; Triticum Aestivum

\section{Introduction}

Microspores are haploid spores that develop into male gametophytes in heterosporous plants. Immature microspores can be stimulated in vitro to form embryos and eventually develop to mature plants. Microspore culture (androgenesis) is currently used to produce double haploid plants for breeding and genetic research to obtain homozygous lines [1-4]. Androgenesis has been apllied to more than 250 plant species $[5,6]$. Wheat double haploid lines obtained through maize pollination and anther culture methods are being cultivated $[7,8]$. However, the application of androgenesis in a number of crops including wheat still requires improvement because many lines are recalcitrant, have a very low response to the protocol and/or often produce a high percent of albinos. Thus, in wheat, microspore culture manipulation of conventional protocols physically and/or chemically is one approach to maximize the production of green plants [9]. Exogenous application of polyamines (PAs) to wheat anthers im- proved the green plant regeneration but overall effect was dependent on duration of the pretreatment and on the genotype [10].

The involvement of PAs in plant morphogenesis, root growth, flower initiation and pollen is well documented [11-13]. Polyamines are nitrogen containing compounds of low molecular weight found in plants and animals. The major forms: putrescine, spermidine and spermine are present in all parts of the cell including the nucleus [14] and appear to participate in all cell processes [12]. Polyamines in plants can serve as intracellular mediators of hormonal activity [11]. The greening or antisenescence role or effect of polyamines has been reported in freshly isolated oat protoplasts [15] and spermine and spermidine were involved in the retention of chlorophyll and stabilization of thylakoid membranes $[16,17]$. Current research on PAs is also devoted to the amelioration of abiotic stresses such as osmotic stress, drought, heat, chilling, light intensity, mineral nutrient deficiency and 
UV irradiation [18]. Although PAs have been studied in somatic embryogenesis in tissue culture $[19,20]$ and in androgenesis $[10,21]$, the effects of these compounds in microspore culture in wheat lines still require investigations to improve green plant regeneration.

PAs and trehalose accumulate and act as compatible solutes in a number of stressed plants. Trehalose, a nonreducing disaccharide, is found in some organisms including a number of plants in which it serves as an osmoprotectant. It stabilizes proteins and biological membranes under a variety of stress conditions including hydrostatic pressure and osmotic stress [22]. Other proposed roles of trehalose include regulation of carbohydrate utilization, plant growth and development [23], especially in regulation of embryo maturation [24]. However, the effects of trehalose in wheat microspore culture have not been studied. Currently, a number of drought tolerant hexaploid wheat genotypes from International Centre for Agricultural Research in the Dry Areas, Allepo, Syria (ICARDA) are being evaluated under our local semi-arid conditions; hopefully using double haploid plants. This study screened microspore culture of three wheat genotypes for its application in our local breeding and biotechnology programs. The objective of this work was to investigate a protocol for efficient wheat microspore culture by the application of polyamines and trehalose, (two compatible solutes involved in plant growth and development) to wheat microspores to improve or increase the number of microspore-derived double haploid green plants.

\section{Materials and Methods}

\subsection{Plant Material}

Three spring wheat genotypes were used in the study. The genotype DH83Z118.32 was selected for its agronomic traits by the breeding department of the Swiss Federal Research Station, Zurich-Reckenholz (FAL) and for its high androgenetic response by ETH Zurich, Switzerland [25]. Its androgenetic response was confirmed for anther as well as isolated microspore culture. The other two lines ICARDA17 and ICARDA39 were from the International Center for Agricultural Research in the Dry Areas (ICARDA), Aleppo, Syria. The anther culture response for a number of ICARDA genotypes including ICARDA17 and 39 was examined in an earlier study [10]. Seeds were germinated at $25^{\circ} \mathrm{C}$ and after 10 days seedlings were planted in peat moss in $10 \mathrm{~cm}$ diameter pots, then placed in growth chambers at a temperature cycle of $23 / 18^{\circ} \mathrm{C}$ day/night, $16 \mathrm{~h}$ photoperiod and $290-310$ $\mu \mathrm{mol} \cdot \mathrm{m}^{-2} \cdot \mathrm{s}^{-1}$ light intensity. After two weeks plants were transplanted to $15 \mathrm{~cm}$ diameter pots.
Spikes were collected when microspores were at midto late-uninucleate stage [26]. The appropriate developmental stage of microspores was determined by spike and anther morphology as well as examination of isolated microspores using acetocarmine stain [27]. Spikes containing mid-to late-uninucleate microspores were wrapped in a foil and kept at $3^{\circ} \mathrm{C}-4^{\circ} \mathrm{C}$ for duration of 7 to 10 days for further studies.

\subsection{Microspore Isolation and Treatment with PAs}

Spikes were surface sterilized with $70 \%$ ethanol and anthers were aseptically removed from the ensheathing leaves into a glass vials containing $3 \mathrm{ml}$ of $\mathrm{AB}$ medium [28]. The microspores were isolated by stirring the anthers in $\mathrm{AB}$ medium with a magnetic bar for $2-3$ min at $600 \mathrm{rpm}$ and the suspension filtered through a $60 \mu \mathrm{m}$ sieve. Microspores were treated with putrecine (Put), spermidine $(\mathrm{Spd})$ and spermine $(\mathrm{Spm})$ alone at $1.0 \mathrm{mM}$ or $0.5 \mathrm{mM}$ combinations of the three PAs. The duration of the treatments was 30 or $60 \mathrm{~min}$ and the microspores were washed twice with $3 \mathrm{ml}$ of $\mathrm{AB}$ medium, centrifuged for $5 \mathrm{~min}$ and the pellet was re-suspended in A2 medium [26]; and counted using a haemocytometer. Microspores were cultured in Petri dishes at a density of $2 \times 10^{4}$ microspores $/ \mathrm{ml}$ with six immature ovaries and incubated at $27^{\circ} \mathrm{C}$ in the dark for 4 days [28].

\subsection{Microspore Culture Conditions}

Microspores were kept at $27^{\circ} \mathrm{C} \pm 1{ }^{\circ} \mathrm{C}$ in the dark for a period of 4 to 6 weeks. Developing embryos $(\geq 2 \mathrm{~mm})$ were sub-cultured on embryo medium (EM) and the regenerated plantlets were transferred to plant regeneration medium (PM), [29]. Phytagel $3 \mathrm{~g} \cdot \mathrm{l}^{-1}$ was added to EM and PM media. The embryos were incubated at $27^{\circ} \mathrm{C}$ with a photoperiod of $16 \mathrm{~h}$ and a light intensity of $30-55$ $\mu \mathrm{mol} \cdot \mathrm{m}^{-2} \cdot \mathrm{s}^{-1}$. Similar conditions were used to regenerate green plants for 3 weeks, which were then transferred to peat moss for [30]. The green plants were maintained in growth chambers till maturity.

\subsection{Viability of PA Treated Microspores}

Viability of microspores treated with different concentrations of PAs or with trehalose was determined by staining with fluorescein diacetate (FDA) solution [31]. The percentage of viable microspores was determined for at least 500 microspores per treatment after 1 and 3 days under fluorescent microscopy. Intense fluorescence and swollen microspores were considered viable, while non-stained and shriveled microspores were considered nonviable. 


\subsection{Treatment of Microspores with Trehalose}

Experimental conditions and media for the evaluation of trehalose treatments were the same as described above. Isolated microspores were treated with $0.1,0.2$ and $0.4 \mathrm{M}$ of trehalose for 1, 2 and 3 days, and then transferred to A2 medium. Developing embryos were sub-cultured on embryo medium (EM) and regenerated plantlets transferred to plant regeneration medium (PM) under the culture conditions described above.

\subsection{Determination of Ploidy Level}

Ploidy of regenerants was estimated using Partec CyFlow space flow cytometer, (Partec GmbH, Münster, Germany) and the data analysis was performed with FloMax software, version 3, after transferring the plantlets to soil. Samples were prepared using young emerging leaves of 10 - 12 day-old seedling. Young leaves were fixed in ethanol-glacial acetic acid $(3: 1 \mathrm{v} / \mathrm{v})$. Leaves were chopped at $4^{\circ} \mathrm{C}$ using a razor blade in $2 \mathrm{ml}$ of Partec DNA staining solution. Extracts with nuclei were filtered through a $30 \mu \mathrm{m}$ nylon gauze filter. More than $3000 \mathrm{nu}-$ clei were counted per sample. Leaf samples from seedlings of each genotype were used as reference. Ploidy level of each sample was estimated by comparing the peaks of histograms of the regenerated green plants to that of its standard genotype (2n) as a control.

Green regenerated plantlets from the three wheat genotypes were grown in the greenhouse and evaluated for fertility and seed setting. Inflorescence of each plant was protected from out-crossing using pollination bags during flowering. Percentage of seed setting by plants of each treatment was determined by checking for viable seeds.

\subsection{Evaluation of Androgenic Response}

Embryogenesis was recorded as the percentage of developed embryos (Embryos/100 microspores), green regenerated plants (GRP/100 embryos), albino and total regenerated plants per 100 microspores were also recorded. Data were statistically analyzed using ANOVA and means were separated by Duncan's multiple range test (DMRT) with MSTAT-C, University of Michigan Statistical package.

\section{Results}

\subsection{Microspore Viability}

Microspores harvested from the middle portion of inflorescence of the three donor plants were mostly in mid- to late-uninucleate stage (Figure 1). They were generally spherical in shape, thin to dense cell walls with a large nucleus that was off-centered and very close to the cell wall.

Viable microspores treated with PAs or trahalose showed intense fluorescence and were larger or swollen, while nonviable ones were shriveled or misshaped (Figure 2). Regardless of the concentration of the PA treatments, the viability of the ICARDA17 and 39 microspores significantly declined $(\mathrm{P} \leq 0.05)$ within 3 days (Figures 3(a) and (b)). Similarly, viability declined with increased concentration and duration of trehalose treatments (data not shown).

Multicellular structures or pro-embryos emerged from the exine wall of microspores within 7 - 10 days (Figure 4) which developed into mature embryos after 4 weeks on EM medium.

\subsection{Effect of PAs on Microspore Cultures}

Generally, ICARDA39 produced the highest number of

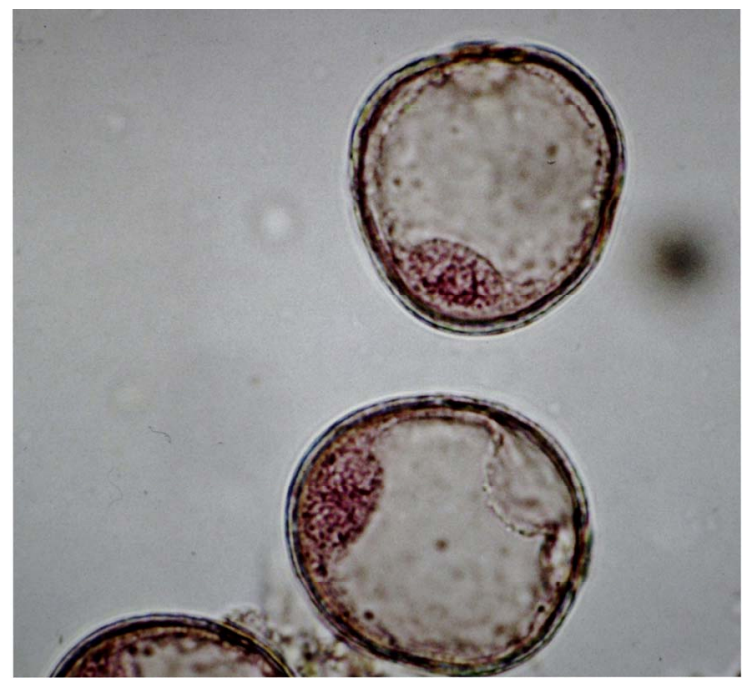

Figure 1. Light microscopy of isolated wheat microspore at mid-to late uninucleate stage $(40 \times)$.

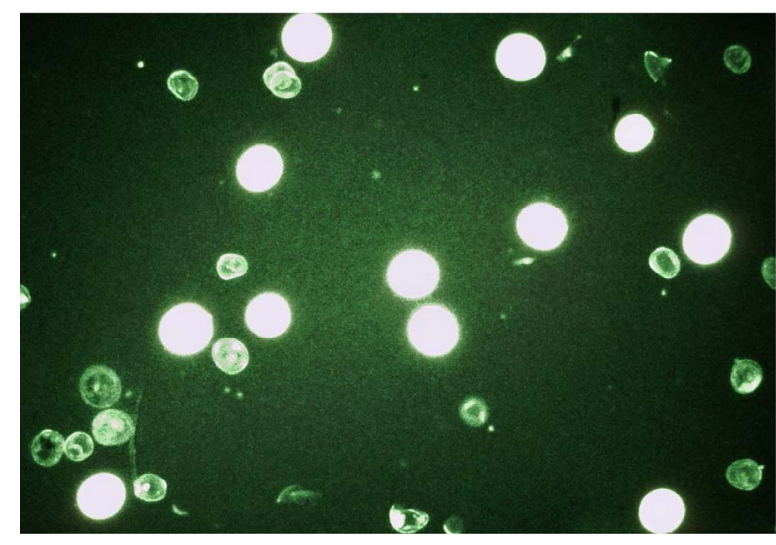

Figure 2. Fluorescent microcopy of viable microspores stained with fluorescein diacetate. Non-viable microspores were shriveled, or misshaped and not-stained. 


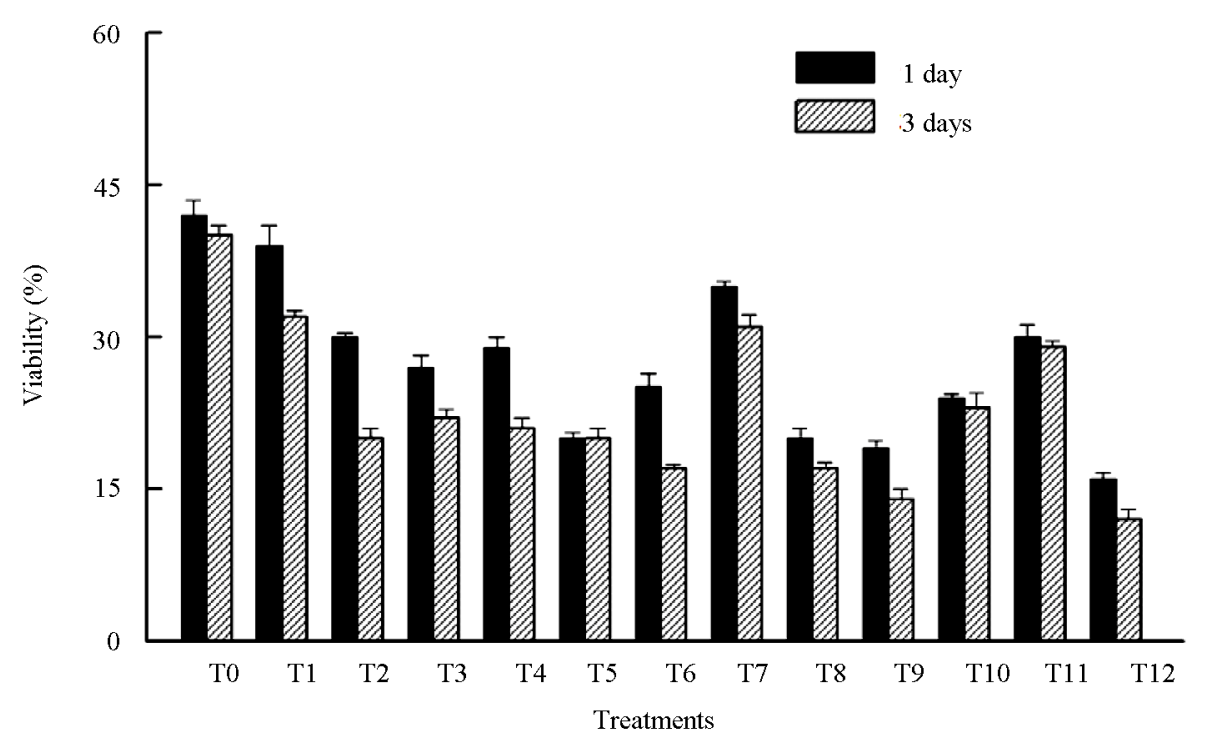

(a)

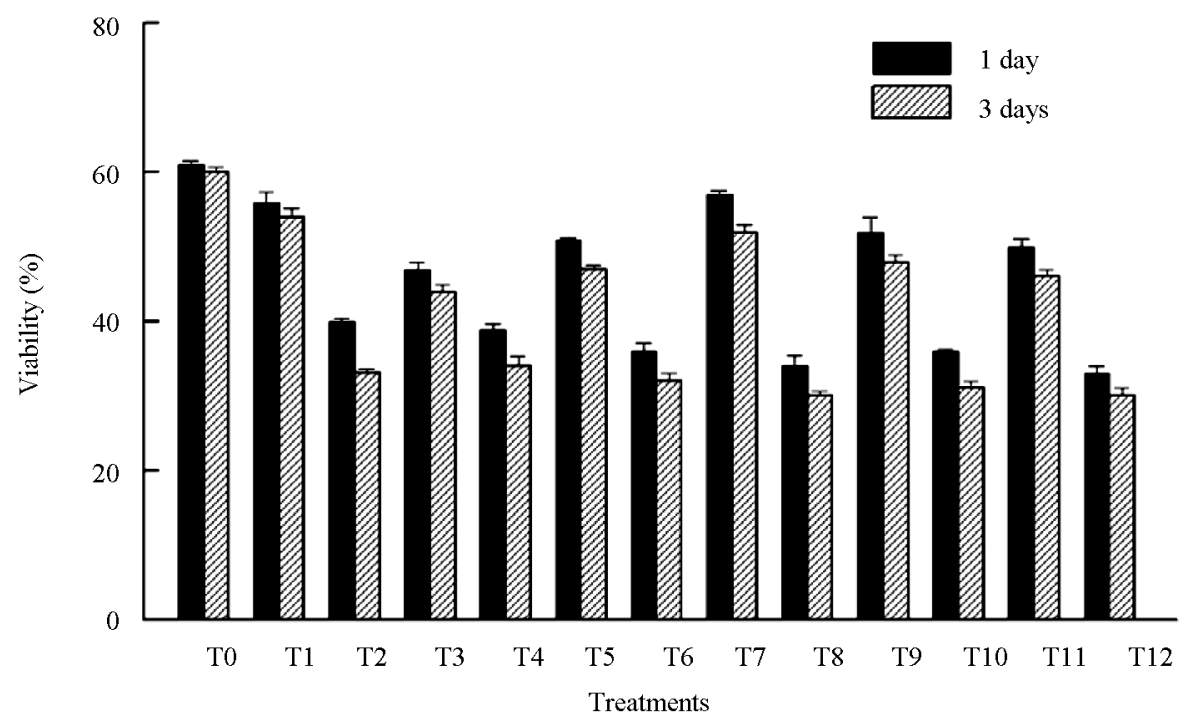

(b)

Figure 3. Percent viability of microspores treated with PAs after 1 - 3 days (a) viable microspore in ICARDA17 and (b) in ICARDA39. Abbreviations for treatments: T0 = control; T1 = $1 \mathrm{mM}$ Put; T2 = $1 \mathrm{mM}$ Spd; T3 = $1 \mathrm{mM}$ Spm; T4 = 0.5 mM (Put + Spd); T5 = $0.5 \mathrm{mM}($ Put + Spm); T6 = $0.5 \mathrm{mM}($ Spd + Spm); and for $60 \mathrm{~min}$ T7 = $1 \mathrm{mM}$ Put; T = $8 \mathrm{mM} \mathrm{Spd;} \mathrm{T9} \mathrm{=} 1$ mM Spm; T10 = 0.5 mM (Put + Spd); T11 = 0.5 mM (Put + Spm); T12 = 0.5 mM (Spd + Spm); The bars represent the standard error of the mean.

GRPs per 100 embryoids compared to the other two genotypes in the 30 min PA treatments (Figure 5(a)). Two PA treatments, 1.0 mM Put and $1.0 \mathrm{mM}$ Spm for 30 min produced the highest number of GRPs/100 embryoids in ICARDA39 whiles in DH83Z, the $0.5 \mathrm{mM}$ combination treatments of $(\mathrm{Put}+\mathrm{Spm})$ and $(\mathrm{Spm}+\mathrm{Spd})$ yielded the highest GRPs/100 embryoids (Figure 5(a)). Embryos in 60 min treatments of DH83 Z and ICARDA17 developed less but significant number of green plants (Figure 5(b)). A high percent $(52 \%-58 \%)$ of these em- bryos in these treatments however, developed into greenish calli with adventitious roots.

Green regenerated plants (GRPs) per 100 microspores in the genotype ICARDA17 was not significantly different among 30 min PA treatments (Figure 6(a)) but ICARDA 39 and DH83Z produced significant numbers of green plants among PA treatments. The highest number of GRPs/100 microspores was in DH83Z treated with $1 \mathrm{mM}$ Spm alone and $0.5 \mathrm{mM}$ combinations of PAs. The number of GRPs produced in the 60 min PA treatments 


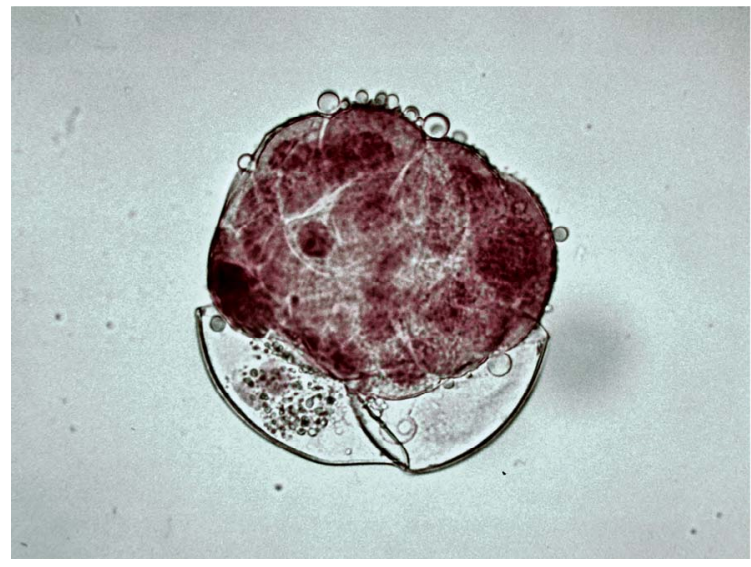

Figure 4. Multinucleate structure or a pro-embryo from a microspore 7 - 10 days after treatment with Pas.

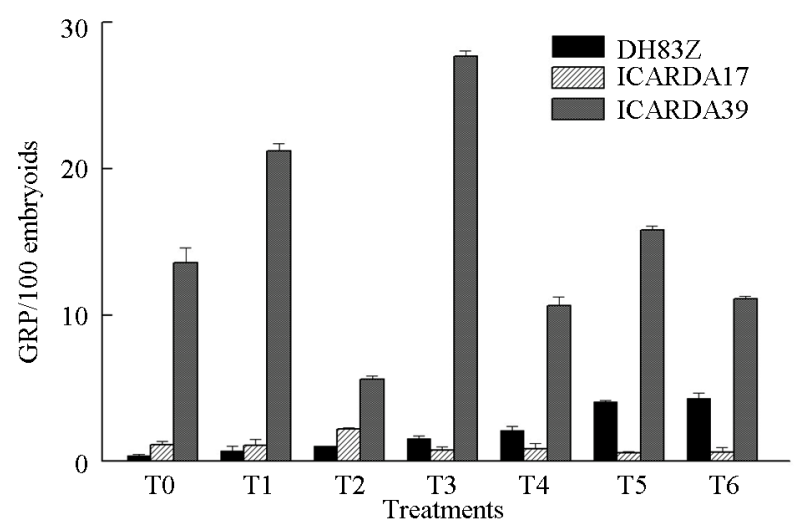

(a)

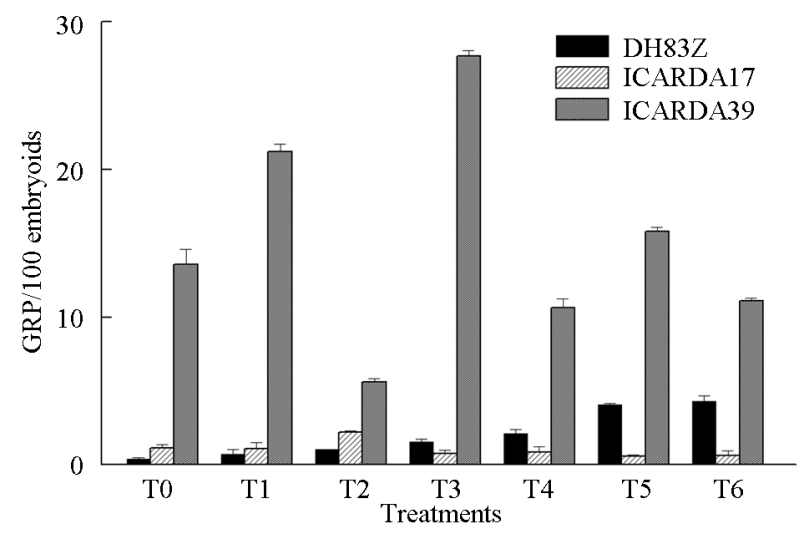

(b)

Figure 5. GRPs per 100 embryos for three wheat genotype microspores treated with PAs for (a) $30 \mathrm{~min}$ and (b) $60 \mathrm{~min}$. Abbreviations for treatments: T0 = control; T1 = 1 mM Put; T2 = 1 mM Spd; T3 = 1 mM Spm; T4 = 0.5 mM (Put + Spd); T5 $=0.5 \mathrm{mM}($ Put + Spm); T6 = $0.5 \mathrm{mM}($ Spd + Spm) . The bars represent the standard error of the mean.

was also significantly different in the genotypes $(\mathrm{P} \leq$ 0.05 ) but PA treatments for 30 min generally produce more GRPs per 100 microspores than the 60 min treat-

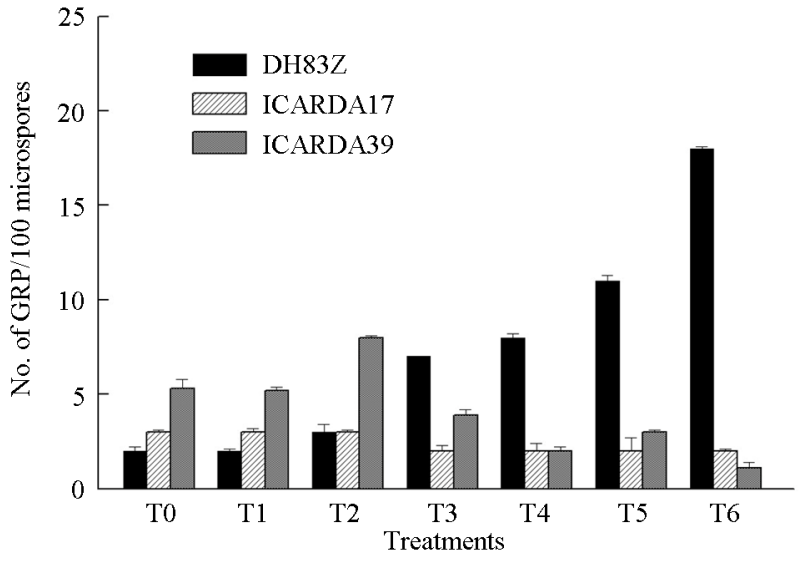

(a)

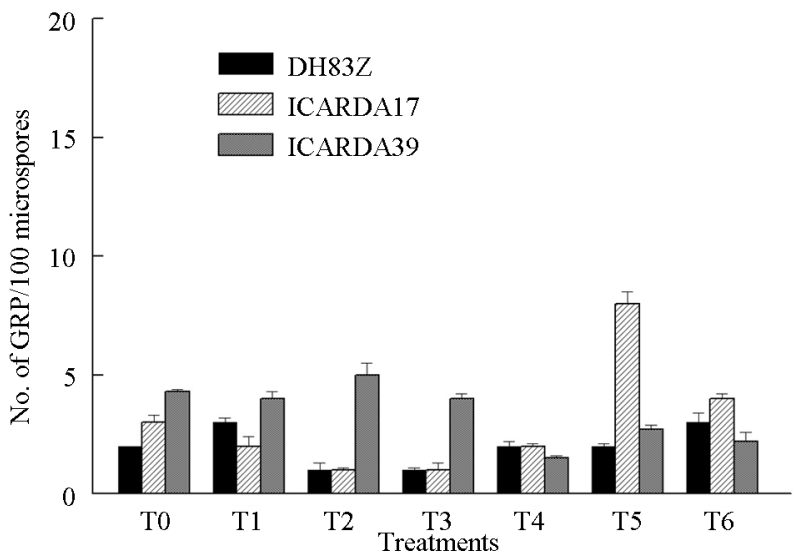

(b)

Figure 6. GRPs per 100 microspores produced from PAs treatments to microspores for (a) $30 \mathrm{~min}$ and (b) $60 \mathrm{~min}$ for three wheat genotypes. Abbreviations for treatments: T0 = control; T1 = 1 mM Put; T2 = 1 mM Spd; T3 = 1 mM Spm; T4 = $0.5 \mathrm{mM}$ (Put + Spd); T5 = $0.5 \mathrm{mM}$ (Put + Spm); T6 = $0.5 \mathrm{mM}$ (Spd + Spm). The bars represent the standard error of the mean.

ments (Figure 6(b)). Microspores from ICARDA17 produced 1.5 times GRPs. Figures $\mathbf{7 ( a )}$ and (b) show representative green and albino plantlets obtained on PM medium.

\subsection{Effect of Trehalose}

Treatment of microspores with trehalose resulted in total inhibition of embryogenesis in DH83Z but in genotypes ICARDA17 and 39 less than 10 embryoids developed per treatment which were significantly lower compared to the control treatments. None of these embryos developed into albino or green plants. Trehalose treatment at $0.4 \mathrm{M}$ did not produce any embryos in all 3 genotypes.

\subsection{Ploidy Analysis}

Figures 8(a) and (b) show ploidy levels of GRPs deter- 


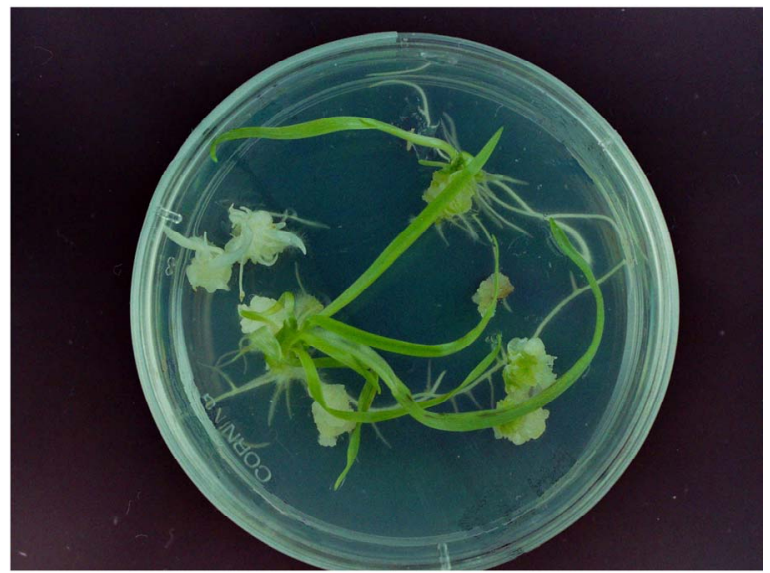

(a)

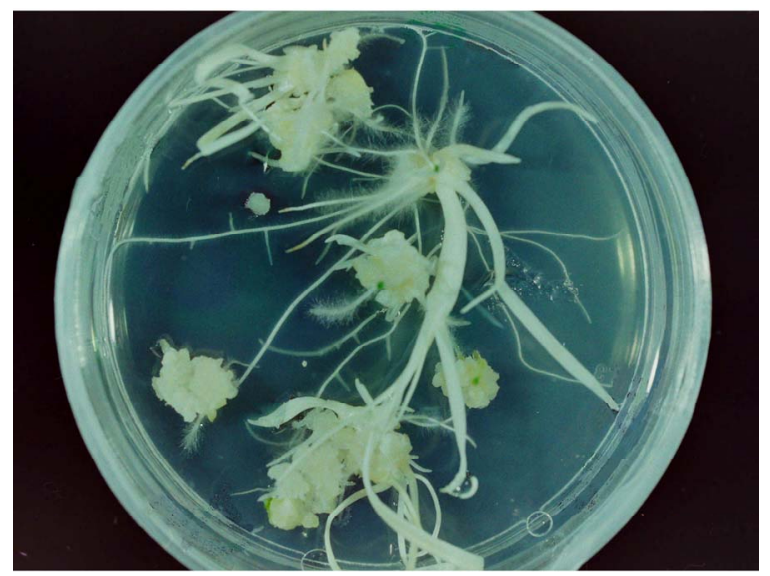

(b)

Figure 7. Plantlets obtained after PA treatments: (a) green regenerated plantlets and (b) albino plants.

mined by flow cytometry based on the relative fluorescence intensity of stained nuclei in haploid and double haploid plants. Double haploid plants occurred in all three genotypes but not in all treatments. Seed setting in DH83Z was $20.4 \%$ to $33.3 \%$; in ICARDA 17 it was $11.1 \%$ to $26.7 \%$ and $15.2 \%$ to $24.1 \%$ in ICARDA39. The range of seed setting in controls was $12.43 \%$ to $16.85 \%$. Nine PA treatments in DH83Z were able to set seeds, with three of them over $25 \%$ (Table 1). In ICARDA39 only two treatments failed to set seeds but seed setting was less than $25 \%$ in all the treatments. ICARDA 17 showed the lowest seed setting with only 4 treatments setting seeds. Seed setting in control treatments of DH83Z and ICARDA39 were lower compared to PA treatments. Figure 9 shows representative potted green fertile regenerants of the wheat genotypes.

\section{Discussion}

Polyamines play a positive role in plant growth and developmental processes including cell division, embryo-

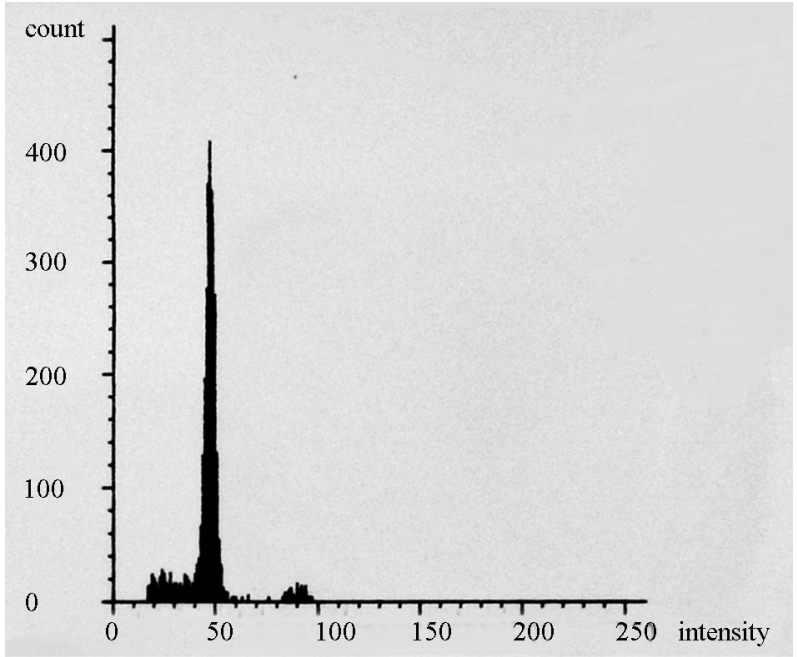

(a)

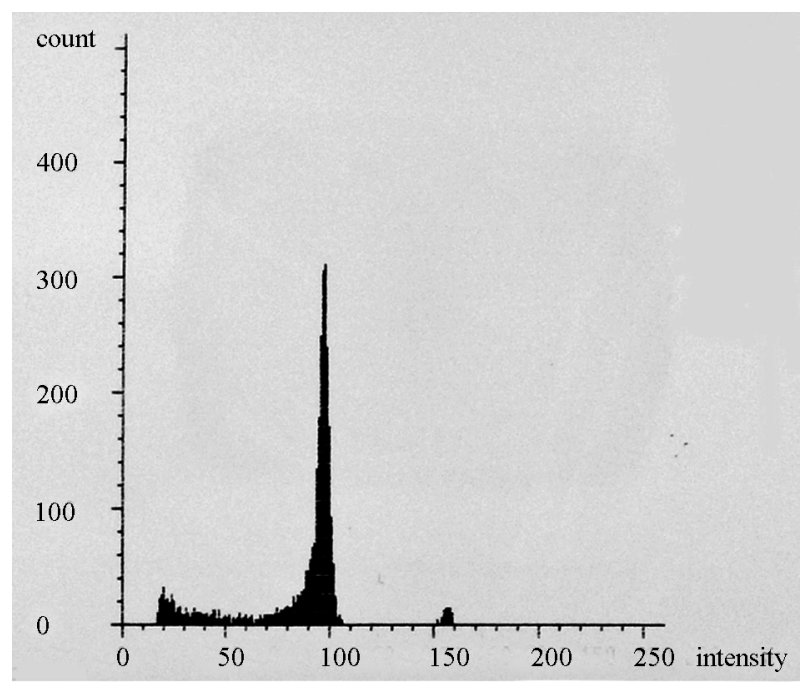

(b)

Figure 8. Flow cytometry histograms depicting ploidy of regenerated plants from PA treated microspores: (a) ploidy of haploid plants and (b) double haploid regenerants.

Genesis, and in tissue culture systems they play a positive role in morphogenesis [32,33]. PAs have also resulted in inhibitory effects in somatic embryos [34] and embryo abnormalities [35]. In this study PAs produced positive results in two of the wheat lines (DH83Z and ICARDA39). PAs applied to microspores for $30 \mathrm{~min}$ improved the regeneration of green plants compared to the 60 min pretreatments. Putrescine combined with Spd or Spm significantly increased GRPs in DH83Z and ICARDA17 but in ICARDA39; $1.0 \mathrm{mM}$ Spd applied for 30 min significantly improved GRPs. The production of GRPs in ICARDA17 improved in $0.5 \mathrm{mM}$ (Put + Spd) and $0.5 \mathrm{mM}(\mathrm{Spd}+\mathrm{Spm})$ in the 60 min treatments. It is apparent from these observations that the need and role for PAs may be limited in some genotypes of wheat. 
Table 1. Effect of PAs on percent seed setting of microspore derived plants in three wheat genotypes.

\begin{tabular}{|c|c|c|c|c|}
\hline & \multirow{2}{*}{ PA Treatments } & \multicolumn{3}{|c|}{ Genotype } \\
\hline & & DH83Z & ICARDA17 & ICARDA39 \\
\hline T0 & Control & 16.85 & 16.06 & 12.43 \\
\hline $\mathrm{T} 1$ & $1.0 \mathrm{mM}$ put for $30 \mathrm{~min}$ & 23.33 & 26.67 & 17.81 \\
\hline $\mathrm{T} 2$ & $1.0 \mathrm{mM}$ spd for $30 \mathrm{~min}$ & 20.40 & 11.11 & 18.55 \\
\hline $\mathrm{T} 3$ & $1.0 \mathrm{mM} \mathrm{spm}$ for $30 \mathrm{~min}$ & 0 & 20.00 & 0 \\
\hline $\mathrm{T} 4$ & $0.5 \mathrm{mM}($ put $+\mathrm{spd})$ for $30 \mathrm{~min}$ & 33.33 & 17.23 & 24.06 \\
\hline T5 & $0.5 \mathrm{mM}(\mathrm{put}+\mathrm{spm})$ for $30 \mathrm{~min}$ & 20.83 & 0 & 16.67 \\
\hline T6 & $0.5 \mathrm{mM}(\mathrm{spd}+\mathrm{spm})$ for $30 \mathrm{~min}$ & 21.97 & 0 & 0 \\
\hline $\mathrm{T} 7$ & $1.0 \mathrm{mM}$ put for $60 \mathrm{mins}$ & 0 & 0 & 21.21 \\
\hline $\mathrm{T} 8$ & $1.0 \mathrm{mM}$ spd for $60 \mathrm{mins}$ & 29.17 & 0 & 15.15 \\
\hline T9 & $1.0 \mathrm{mM} \mathrm{spm}$ for $60 \mathrm{mins}$ & 23.54 & 0 & 15.56 \\
\hline $\mathrm{T} 10$ & $0.5 \mathrm{mM}$ (put + spd) for $60 \mathrm{mins}$ & 0 & 0 & 21.67 \\
\hline $\mathrm{T} 11$ & $0.5 \mathrm{mM}(\mathrm{put}+\mathrm{spm})$ for $60 \mathrm{mins}$ & 21.21 & 0 & 18.43 \\
\hline $\mathrm{T} 12$ & $0.5 \mathrm{mM}(\mathrm{spd}+\mathrm{spm})$ for $60 \mathrm{mins}$ & 29.82 & 0 & 20.32 \\
\hline
\end{tabular}

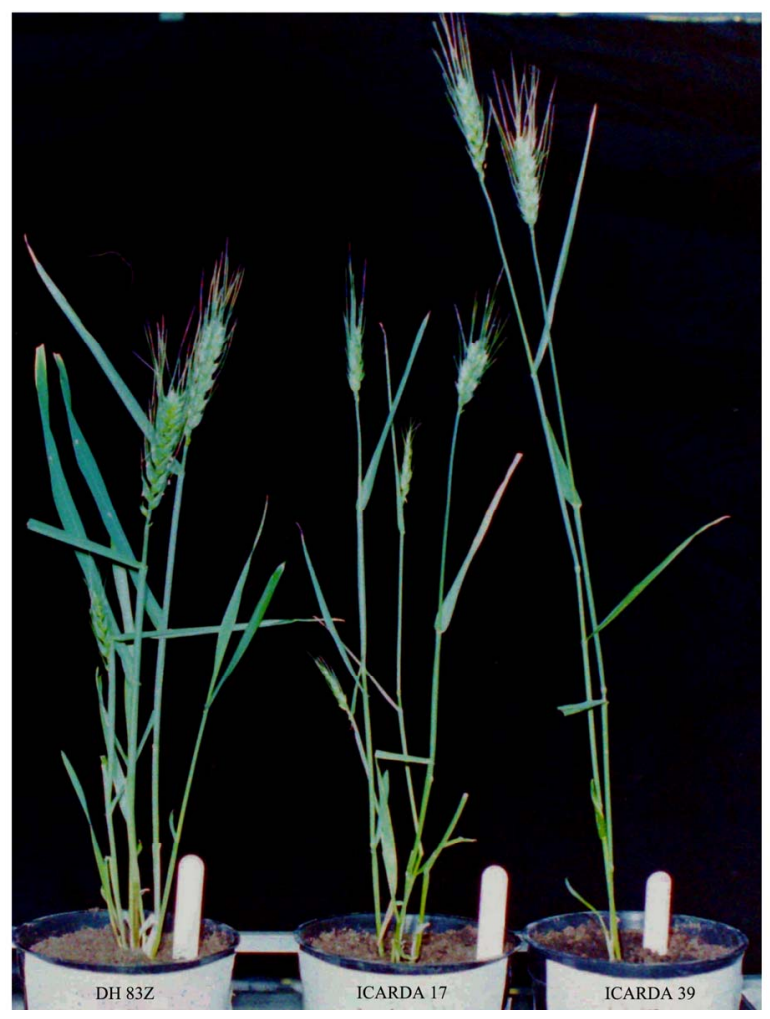

Figure 9. Representative potted double haploid plants from PA treated microspore culture of wheat genotypes.

Polyamines in this study also induced the formation of embryos that developed into calli with adventitious roots which is in agreement with the observations of other researchers $[28,36]$. Some of these embryos developed into greenish calli which has been observed in wheat anther culture [10], in rice anther culture [37] and this could be due to the presence of Spd and Spm which have been shown to retain chlorophyll as well as stabilize thylakoid membranes [38]. Undifferentiated greenish embryo cells in wheat anther culture pretreated with PAs have been shown to contain numerous agranal-like chloroplasts [10].

Both trehalose and PAs have the capacity to alleviate osmotic stress in plants. In this study embryogenesis and regeneration of green plants were dependent on the type as well as the concentration of osmoticum used because trehalose and PA exhibited contradictory results. Similar observations were observed with manitol in microspore cultures in barley [39] and durum wheat [4]. In this study the significant impact of PAs in wheat microspore culture was in embryogenesis which resulted in increased green plant regenerants.

Also in this study lower numbers of double haploid plants were produced in controls compared to PA treatments and flow cytometry results using very young leaves were very similar to the percent of seed setting and to a large extent indicative of the fertility of the green regenerated plants.

Finally, the results of this study showed that the application of $1.0 \mathrm{mM}$ Put, Spd and Spm alone or $0.5 \mathrm{mM}$ combinations of these PA treatments on isolated microspores for $30 \mathrm{~min}$ improved the embryogenesis and production of green plants in ICARDA39 and DH83Z genotypes. Application of $0.1-0.4 \mathrm{M}$ trehalose to microspores however, had no impact on embryogenesis and regeneration of plants. The effectiveness of PAs in wheat microspore culture depended on the concentration and duration of PA treatments as well as the genotype. Treatment of microspores with polyamines not only im- 
proved plant regeneration but also significantly improved seed setting and could be used to accelerate some cultivar development in wheat breeding programs.

\section{Acknowledgements}

The Authors thank Research Administration of Kuwait University for funding this project (\# SL04/06). We also thank Cynthia A. Menezes who was the Research Assistant for the project.

\section{REFERENCES}

[1] Y. P. S. Bajaj, "In-Vitro Production of Haploids and Their Use in Cell Genetics and Plant Breeding," In: Y. P. S. Bajaj, Ed., Biotechnology in Agriculture and Forestry. Haploids in Crop Improvement, Springer-Verlag, Berlin, Heidelberg, 1990, pp. 3-44. http://dx.doi.org/10.1007/978-3-642-61499-6_ 1

[2] S. Teparkum and R. E. Veilleux, "Indifference of Potato Anther Culture to Colchicine and Genetic Similarity among Anther-Derived Monoploid Regenerants Determined by RAPD Analysis," Plant Cell Tissue and Organ Culture, Vol. 53, No. 1, 1998, pp. 49-58. http://dx.doi.org/10.1023/A:1006099423651

[3] B. P. Forster, E. Heberle-Bors, K. J. Kasha and A. Touravev, "The Resurgence of Haploids in Higher Plants," Trends in Plant Science, Vol. 12, No. 8, 2007, pp. 368375. http://dx.doi.org/10.1016/j.tplants.2007.06.007

[4] O. Slama-Ayed, J. De Buyser, E. Picard, Y. Trifa and H. S. Amara, "Effect of Pretreatment on Isolated Microspore Culture Ability in Durum Wheat (Triticum turgidum subsp. durum Desf.)," Journal of Plant Breeding and Crop Science, Vol. 2, No. 2, 2010, pp. 30-38.

[5] P. S. Baeziger, W. K. Russell, G. L. Graef and B. T. Campbell, "Improving Lives: 50 Years of Crop Breeding, Genetics and Cytology (C-1)," Crop Science, Vol. 46, No. 5, 2006, pp. 2230-2244.

http://dx.doi.org/10.2135/cropsci2005.11.0404gas

[6] A. Touraev, B. P. Foster and S. M. Jain, "Advances in Haploid Production in Higher Plants," Sringer Science + Business Media B.V., Dordrecht, 2009, pp. 1-208.

[7] J. Guzy-Wróbelska and I. Szarejko, "Molecular and Agronomic Evaluation of Wheat Double Haploid Lines Obtained through Maize Pollination and Anther Culture Methods," Plant Breeding, Vol. 122, No. 4, 2003, pp. 305-313.

http://dx.doi.org/10.1046/j.1439-0523.2003.00858.x

[8] S. K. Basu, M. Datta, M. Sharma and A. Kumar, "Haploid production technology in wheat and some selected higher plants," Australian Journal of Crop Science, Vol. 5, No. 9, 2011, pp. 1087-1093.

[9] M. Y. Zheng, "Microspore Culture in Wheat (Triticum aestivum)-Doubled Haploid Production via Induced Embryogenesis," Plant Cell Tissue and Organ Culture, Vol. 73, No. 3, 2003, pp. 213-230. http://dx.doi.org/10.1023/A:1023076213639
[10] A. Redha and P. Suleman, "Effect of Exogenous Application of Polyamines on Wheat Anther Cultures," Plant Cell Tissue and Organ Culture, Vol. 105, No. 3, 2010, pp. 345-353. http://dx.doi.org/10.1007/s11240-010-9873-7

[11] H. P. Bais and G. A. Ravishankar, "Role of Polyamines in the Ontogeny of Plants and Their Biotechnological Applications," Plant Cell Tissue and Organ Culture, Vol. 69, No. 1, 2002, pp. 1-34. http://dx.doi.org/10.1023/A:1015064227278

[12] A. Bouchereau, A. Azis, F. Larher and J. Martin-Tanguy, "Polyamines and Environmental Challenges: Recent Development," Plant Science, Vol. 140, No. 2, 1999, pp. 103-125. http://dx.doi.org/10.1016/S0168-9452(98)00218-0

[13] J. Martin-Tanguy, "Metabolism and Function of Polyamines in Plants: Recent Development (New Approaches)," Plant Growth Regulation, Vol. 34, No. 1, 2001, pp. 135-148. http://dx.doi.org/10.1023/A:1013343106574

[14] V. Kuznetsov, N. L. Radyukina and N. I. Shevyakova, "Polyamines and Stress: Biological Role, Metabolism, and Regulation," Russian Journal of Plant Physiology, Vol. 53, No. 5, 2006, pp. 583-604. http://dx.doi.org/10.1134/S1021443706050025

[15] A. Altman, R. Kaur-Sawhney and A. W. Galston, "Stabilization of Leaf Protoplast through Polyamine-Mediated Inhibition of Senescence," Plant Physiology, Vol. 60, No. 4, 1977, pp. 570-574. http://dx.doi.org/10.1104/pp.60.4.570

[16] R. T. Besford, C. Richardson, J. L. Campos and A. F. Tiburcio, "Effect of Polyamines on Stabilization of Molecular Complexes in Thylakoid Membranes of Osmotically-Stressed Oat Leaves," Planta, Vol. 189, No. 2, 1993, pp. 201-206. http://dx.doi.org/10.1007/BF00195077

[17] A. F. Tiburcio, R. T. Besfor, T. Capell, A. Borrell, P. S. Testillano and M. C. Rsueno, "Mechanisms of Polyamine Action during Senescence Response Induced by Osmotic Stress," Journal of Experimental Botany, Vol. 45, No. 12, 1994, pp. 1789-1800. http://dx.doi.org/10.1093/jxb/45.12.1789

[18] K. Gupta, A. Dey and B. Gupta, "Plant Polyamines in Abiotic Stress Responses," Acta Physiologiae Plantarum, Vol. 35, No. 7, 2013, pp. 2015-2036. http://dx.doi.org/10.1007/s11738-013-1239-4

[19] C. Kevers, T. Gaspar and D. Jacques, "The Beneficial Role of Different Auxins and Polyamines at Successive Stages of Somatic Embryo Formation and Development of Panax ginseng in Vitro," Plant Cell Tissue and Organ Culture, Vol. 70, No. 2, 2002, pp. 181-188. http://dx.doi.org/10.1023/A:1016399905620

[20] M. K. Rajesh, E. Radha, K. Anitha and V. A. Parthasarathy, "Plant Regeneration from Embryo-Derived Callus of Oil Palm-The Effect of Exogenous Polyamines," Plant Cell Tissue and Organ Culture, Vol. 75, No. 1, 2003, pp. 4147. http://dx.doi.org/10.1023/A:1024679910085

[21] B. P. Hema and H. N. Murthy, "Improvement of in Vitro Androgenesis in Niger Using Amino Acids and Polyamines," Biologia Plantarum, Vol. 52, No. 1, 2008, pp. 
121-125. http://dx.doi.org/10.1007/s10535-008-0024-5

[22] N. Benaroudj, D. H. Lee and A. L. Goldberg, "Trehalose Accumulation during Cellular Stress Protects Cells and Cellular Proteins from Damage by Oxygen Radicals," Journal of Biological Chemistry, Vol. 276, 2001, pp. 24261-24267. http://dx.doi.org/10.1074/jbc.M101487200

[23] H. Schluepmann, A. van Dijken, M. Aghdasi, B. Wobbes, M. Paul and S. Smeekens, "Trehalose Mediated Growth Inhibition of Arabidopsis Seedlings Is Due to Trehalose6-Phosphate Accumulation," Plant Physiology, Vol. 135, No. 2, 2004, pp. 879-890. http://dx.doi.org/10.1104/pp.104.039503

[24] P. J. Eastmond, A. van Dijken, M. Spileman, A. Tissier, H. G. Dichinson, J. D. Jones, S. C. Smeekens and I. A. Graham, "Trehalose-6-Phosphate Synthase I, Which Catalalyses the First Step in Trehalose Synthesis, Is Essential for Arabidopsis Embryo Maturation," The Plant Journal, Vol. 29, No. 2, 2002, pp. 225-235. http://dx.doi.org/10.1046/j.1365-313x.2002.01220.x

[25] J. E. Schmid, M. Winzeler, B. Keller, B. Bütter, P. Stamp and H. Winzeler, "Induction and Use of Doubled Haploids in Wheat and Spelt Breeding Programs," In: New Methods in Cereal Breeding, Eucarpia Cerial Section, Prospectives of Cereal Breeding in Europe, Landquart, 1994, pp. 146-147.

[26] A. Touraev, A. Indriato, I. Wratschko, O. Vicente and E. Heberle-Bors, "Efficient Microspore Embryogenesis in Wheat (Triticum aestivum L.) Induced by Starvation at High Temperature," Sexual Plant Reproduction, Vol. 9, No. 4, 1996, pp. 209-215. http://dx.doi.org/10.1007/BF02173100

[27] W. Liu, M. Y. Zheng, E. Polle and C. F. Konzak, "Highly Efficient Doubled-Haploid Production in Wheat (Triticum aestivum L.) via Induced Microspore Embryogenesis," Crop Science, Vol. 42, No. 3, 2002, pp. 686-692. http://dx.doi.org/10.2135/cropsci2002.0686

[28] M. E. Shariatpanahi, K. Belogradova, L. Hessamvaziri, E. Heberle-Bors and A. Touraev, "Efficient Embryogenesis and Regeneration in Freshly Isolated and Cultured Wheat (Triticum aestivum L.) Microspores without Stress Pretreatment," Plant Cell Reports, Vol. 25, No. 12, 2006, pp. 1294-1299. http://dx.doi.org/10.1007/s00299-006-0205-7

[29] J. E. Schmid, "In Vitro Production of Haploids in Triticum spelta," In: Y. P. S. Bajaj, Ed., Biotechnology in Agriculture and Forestry, Vol. 13: Wheat, Springer-Verlag, Berlin, Heidelberg, 1990, pp. 363-381.

[30] A. Redha and T. Attia, "Improvement of Green Plant
Regeneration by Manipulation of Anther Culture Induction Medium of Hexaploid Wheat," Plant Cell Tissue and Organ Culture, Vol. 92, No. 2, 2008, pp. 141-146. http://dx.doi.org/10.1007/s11240-007-9315-3

[31] J. M. Widholm, "The Use of Fluorescein Diacetate and Phenosafranine for Determining Viability of Cultured Plant Cells," Biotechnic \& Histochemistry, Vol. 47, No. 4, 1972, pp. 189-194.

[32] R. Phillips, M. C. Press and A. Eason, "Polyamines in Relation to Cell Division and Xylogenesis in Cultures Explants of Heliantus tuberosus: Lack of Evidence for Growth-Regulatory Action," Journal of Experimental Botany, Vol. 38, No. 1, 1987, pp. 164-172. http://dx.doi.org/10.1093/jxb/38.1.164

[33] I. El-Hadrami, M. P. Carron and J. D'Auzac, "Clonal variability of the embryogenic potential of Hevea brasiliensis: Relations with Polyamines ( PA ) and Peroxidases ( PO ) in Calli," Comptes Rendus-Academie des Sciences Paris, Vol. 308, No. 111, 1989, pp. 299-305.

[34] M. B. P. Calheiros, L. G. E. Vieira and S. R. L. Fuentes, "Effect of Exogenous Polyamines on Direct Somatic Embryogenesis in Coffee," Revista Brasileira de Fisiologia Vegetal, Vol. 6, No. 2, 1994, pp. 109-114.

[35] O. Faure, M. Mengoli, A. Nougarede and N. Bagni, "Polyamine Pattern and Biosynthesis in Zygotic and Somatic Embryo Stages of Vitis vinifera," Journal of Plant Physiology, Vol. 138, No. 5, 1991, pp. 545-549. http://dx.doi.org/10.1016/S0176-1617(11)80238-5

[36] I. Couée, I. Hummel, C. Sulmon, G. Gouesbet and A. El Armani, "Involvement of Polyamines in Root Development," Plant Cell Tissue and Organ Culture, Vol. 76, No. 1, 2004, pp. 1-10. http://dx.doi.org/10.1023/A:1025895731017

[37] I. S. Dewi and B. S. Purwoko, "Role of Polyamines in Inhibition of Ethylene Biosynthesis and Their Effects on Rice Anther Culture Development," Indonesian Journal of Agricultural Science, Vol. 9, No. 2, 2008, pp. 60-67.

[38] A. W. Galston, R. Kaur-Sawhney, T. Atabella and A. F. Tiburcio, "Plant Polyamines in Reproductive Activity and Response to Abiotic Stress," Botanica Acta, Vol. 110, No. 3, 1997, pp. 197-207.

[39] S. Hoekstra, M. H. van Zijderveld, F. Heidekamp and F. van der Mark, "Microspore Culture of Hordeum vulgare L.: The Influence of Density and Osmolality," Plant Cell Reports, Vol. 12, No. 12, 1993, pp. 661-665. http://dx.doi.org/10.1007/BF00233415 